\title{
O TOYOTISMO E A MERCANTILIZAÇÃO DO TRABALHO NA INDÚSTRIA AUTOMOTIVẢ DO BRASIL ${ }^{1}$
}

\author{
Geraldo Augusto Pinto*
}

\begin{abstract}
O objetivo deste artigo é analisar o avanço de conceitos e práticas de gestão do trabalho designados como "flexíveis" na indústria automotiva do Brasil, em especial os oriundos do Sistema Toyota de Produção. Por meio de uma investigação bibliográfica e de um estudo de caso empírico numa planta pertencente a um grupo transnacional do setor de autopeças, situada em Campinas, SP (Brasil), demonstra-se como foram efetuadas alterações na organização do trabalho, concomitantes à exigência de novos perfis de qualificação profissional e educacional aos trabalhadores. Em termos conclusivos, a presente análise evidencia como tais perfis - articulados a métodos gerenciais de avaliação em processos de contratação e promoção - têm fragmentado o coletivo de trabalhadores nas empresas, mercantilizando as relações que estabelecem entre si no cotidiano de trabalho, uma vez que se baseiam na introjeção e manipulação de princípios de conduta entre eles, no sentido de servilizá-los ao propósito da acumulação capitalista.

PALAVRAS-Chave: Sistema Toyota de Produção. Sociologia do Trabalho. Indústria Automotiva Brasil.
\end{abstract}

\section{INTRODUÇÃO}

A emergência e difusão mundial do Sistema Toyota de Produção, com seus métodos peculiares de gestão da força de trabalho, em que formas sutis de envolvimento e controle dos trabalhadores são combinadas a elementos de alta intensificação das funções e tarefas que desempenham, é um assunto que vem sendo investigado há pelo menos duas décadas pelas Ciências Sociais no Brasil, mesmo porque foi a partir dos anos 1990 que a aplicação de tal sistema pelas empresas avançou pelo país, gerando desemprego massivo e es-

* Doutor em Sociologia. Professor do Centro de Educação e Letras da Universidade Estadual do Oeste do Paraná, campus de Foz do Iguaçu.

Avenida Tarquínio Joslin dos Santos, 1300. Cep: 85870-650. Foz do Iguaçu-Paraná-Brasil. geraldoaugusto@hotmail.com

${ }^{1}$ Este texto é uma versão atualizada e aperfeiçoada de um trabalho apresentado no $33^{\circ}$ Encontro Anual da Associação Nacional de Pós-Graduação em Ciências Sociais (ANPOCS) Ele traz análises contidas na tese de Pinto (2011) (IFCH/Unicamp), a qual recentemente foi publicada em livro. Agradecemos à Fundação de Amparo à Pesquisa do Estado de São Paulo (FAPESP) pela bolsa de estudos concedida e ao Prof. Dr. Ricardo Antunes do Instituto de Filosofia e Ciências Humanas da Universidade estadual de Campinas (IFCH/Unicamp) pela orientação da tese de doutorado, cujos resultados apresentamos parcialmente neste artigo. trutural, precarização das condições de trabalho e afrontamento do sindicalismo combativo gestado nas crises das décadas de 1970 e 1980.

O presente artigo se insere nessa seara de estudos, buscando dar relevo a alguns aspectos da totalidade complexa desse processo. Primeiramente, mostrando que a difusão do toyotismo nas economias ocidentais, como ilustra o caso da própria indústria automotiva, não consistiu em uma simples réplica da aplicação desse sistema na organização interna da miríade de plantas já previamente instaladas em diversos pontos do globo. Se, em parte, isso ocorreu, não se deve olvidar o fato de que tal processo foi acompanhado da aplicação conjunta de outras estratégias pela indústria automotiva ocidental, tais como o embasamento na abertura comercial crescente das economias nacionais, por meio do qual essa indústria inicou uma exploração ainda mais rigorosa das "vantagens" comparativas locais, como o elevado estado das artes da tecnologia dos países centrais e o baixo custo das matérias-primas e da força de trabalho na periferia.

Um outro ponto que chama a atenção nesse 
processo é o alto grau de concentração de capital atingido pela indústria automotiva em nível mundial desde então, em meio ao qual o setor de autopeças de países periféricos foi rapidamente desnacionalizado e absorvido por grupos oligopólicos transnacionais estadunidenses, europeus e japoneses. Em tais condições, a gestão de empresas até então nacionais, ainda que mantida sob as mãos de gerências assalariadas locais, foi submetida ao comando férreo de diretorias e presidências de matrizes estrangeiras.

Às gerências locais é dada a missão de não apenas ampliar fatias do mercado de consumo, mas de gerar "taxas extraordinárias" de acumulação. ${ }^{2}$ Com tais objetivos em vista, tais gerências têm investido radicalmente na introdução dos sistemas de gestão flexível da força de trabalho, como o toyotista - exemplo contemporâneo de gestão capitalista mediante o qual se avança na "superexploração" do trabalho, desde as economias centrais até as periféricas.

O objetivo do presente texto é, pois, evidenciar como isso se manifesta na realidade, por meio de informações obtidas em um estudo de caso que realizamos entre 2005-2006, numa empresa sistemista de autopeças de capital transnacional, situada na região de Campinas, interior do Estado de São Paulo, Brasil (Pinto, 2011). Buscaremos demonstrar, partindo das alterações na organização do trabalho na empresa, como as novas exigências de qualificação profissional e educacional, articuladas aos métodos gerenciais de avaliação dos trabalhadores nos processos de contratação e promoção, têm resultado em uma aproximação entre gerências assalariadas e operariado, mediante a qual a lógica da acumulação capitalista transcende o nível das relações entre as empresas nas cadeias produtivas (matrizes e filiais; clientes e fornecedoras), para se instalar nas relações entre os próprios assalariados no ambiente de trabalho.

${ }^{2}$ Como apontara, desde a década de 1970, Ruy Mauro Marin (2008). A atualidade das teses de Marini para explicar o papel desempenhado tanto pelas novas formas de exploração do trabalho sob a difusão do toyotismo, quanto pelas periferias emergentes na divisão internacional do trabalho em meio à sucessão de crises após a década de 1970 , é objeto de diversas pesquisas, como Valencia (2007), Sader e Santos (2009) e Martins (2011).
Entendemos, contudo, que tanto o advento do toyotismo no Japão quanto sua difusão mundial, após os anos 1970, são realidades cuja compreensão é deficitária, se não as admitirmos como momentos de uma totalidade histórica maior, ou seja, como processos de reprodução da acumulação capitalista na insaciável e crônica necessidade de superar suas contradições internas. A seção seguinte, portanto, almeja introduzir o leitor nas considerações de caráter histórico mais amplo sobre a emergência e posterior difusão do sistema toyotista, tendo como foco a indústria automotiva ocidental e suas singularidades. Em seguida, na terceira seção deste artigo, as informações do estudo de caso por nós realizado no Brasil serão analisadas tendo como preliminares tais considerações, incorporando, contudo, os elementos empíricos que nos permitirão encaminhar e defender a tese acima: a mercantilização das relações entre os assalariados no interior das empresas. Essa tese, na última seção do texto, será retomada e exposta na forma de um ensaio curto, embora amplo e ousado, cujo objetivo é menos responder do que provocar questões que instiguem novas investigações sobre o tema.

\section{A EMERGÊNCIA DO SISTEMA TOYOTA DE PRODUÇÃO E AREAÇÃO DA INDÚSTRIA AUTOMOTIVA OCIDENTAL}

Nos países capitalistas centrais do Ocidente, a propriedade privada dos meios de produção admitiu, junto ao surgimento das grandes corporações (sobretudo na primeira metade do século XX), certa multiplicidade de nacionalidades, gerando, especialmente em indústrias avançadas como a automotiva, uma intensa dinâmica concorrencial em termos de saberes e interesses. Nascia, então, uma cultura empresarial liberal, supostamente autonôma em face do Estado e que, por meio de uma rede de grandes empresas de perfil monopolista - ainda que internamente fragmentadas sob a influência de acionistas vorazes e, externamente, individualizadas 
no plano de suas relações no mercado - conformou as bases dos primeiros sistemas de gestão da força de trabalho em uma organização industrial voltada para a produção em massa: o taylorismo, com sua sanha em eliminar todo saber artesanal, e, posteriormente, o fordismo, com a verticalização estandardizada de controle que apregoava.

Mundialmente difundido, inclusive em vários setores econômicos além da indústria, tal estilo ocidental de organização estabeleceu relações contraditórias entre empresas, Estado e classe trabalhadora. Afinal, quando a verticalização administrativa e a monopolização de negócios por grupos transnacionais concorrentes atravessaram crises de acumulação, o seu individualismo econômico-corporativo e o seu liberalismo político-ideológico vieram a ceder espaço, estrategicamente, à intervenção estatal e mesmo à ação sindical para a conservação das formas de acumulação de capital. Provam-no o contexto do pós-1945, quando, em face da emergência de regimes supostamente hostis ao capitalismo, cristalizaram-se padrões de intervenção estatal tanto nos países periféricos, estigmatizados como subdesenvolvidos, quanto nos países centrais, arraigados em seu imperialismo. E foi exatamente em tal contexto que emergiu uma economia de mercado fundada na articulação entre a gestão do trabalho taylorista-fordista ${ }^{3} \mathrm{e}$ as intervenções estatais protecionistas às burguesias nacionais.

Esse período, consagrado por um crescimento econômico relativamente estável e por uma elevação da produtividade do trabalho seguida de relativas melhorias nos níveis de renda e emprego, sofreria, contudo, alterações nos anos 1970, quando uma série de desequilíbrios causados pelo súbito aumento dos preços do petróleo no mercado internacional (em 1973 e 1979) e pelas sucessivas variações do dólar impostas pelos Estados Unidos da América (EUA) (em 1978 e 1985), provocaram fortes oscilações nas

${ }^{3}$ Ao usarmos a expressão "taylorista-fordista", estamos nos referindo ao próprio sistema fordista. Nosso intuito, entretanto, é deixar subentendido que o sistema desenvolvido por Ford dependeu e foi plenamente viabilizado pela anterior difusão das práticas tayloristas. Especificamente a esse respeito, consultar Pinto (2007a, 2010a). taxas de câmbio em quase todos os países. Desde então, não só se acentuou uma abertura comercial das economias nacionais, como se avolumaram os investimentos financeiros especulativos, dada a instabilidade das moedas e as ágeis operações permitidas pela microeletrônica aplicada à informação (Dedecca, 1998; Harvey, 1992; Mattoso, 1994; Quadros, 1991; Tavares,1992).

Tal panorama, ao passo que acautelou investimentos nos setores industriais das economias centrais, promoveu uma hipertrofia dos setores de serviços, como o comércio e as finanças. O deslocamento de demandas gerado por esses novos segmentos e o baixo crescimento econômico em geral (se comparado aos índices do pós-1945 até fins dos anos 1960), pressionaram as empresas a reverem suas estratégias de gestão, entre as quais adquiriram importância central a agregação de novas tecnologias, a redução de custos de produção e a personalização de seus processos e produtos. Tais iniciativas, no entanto, exigiam de cada companhia alcançar patamares mínimos de: (1) flexibilidade, ou capacidade de ofertar diferentes tipos de produtos e serviços num curto período de tempo, mantendo-se ou não a larga escala; (2) qualidade, ou redução de custos de re-trabalho, eliminando-se falhas em processo; (3) baixos preços finais, obtidos não apenas pela qualidade e flexibilidade, mas pelo enxugamento, ou seja, a redução de toda capacidade ociosa em termos de equipamentos e força de trabalho; (4) atendimento preciso, isto é, no momento, na quantidade e nas características exatamente estipuladas pela clientela, sem gerar atrasos, tampouco estoques.

Tais objetivos colocaram em questão a organização verticalizada e concentradora de grandes contingentes de trabalhadores, demasiadamente especializados e pouco qualificados, do sistema taylorista-fordista. Da perspectiva das relações entre gerência e operariado, esse sistema experimentava a reação mais crua da própria "natureza" humana, cuja formação física e mental nunca foi para isso voltada: o velho dilema de Taylor - a conquista da "iniciativa" dos as- 
salariados - persistia e, desde os anos 1930, pesquisas sobre as condições de trabalho conjeturavam acerca do estancamento da produtividade e da crescente insatisfação entre os trabalhadores. ${ }^{4}$ Por outro lado, a imprevisibilidade de mensuração da mais-valia - pois não é dado às empresas saberem, de antemão, qual é a taxa exata que lhe renderá cada trabalhador individualmente--, sempre foi um problema na gestão capitalista do trabalho: ou seja, implanta-se um sistema e logo se desenvolvem resistências (Oliveira, 1996). Ora, se o taylorismo já enfrentara contestações sindicais e até mesmo jurídicas no início do século XX, o desenrolar das lutas sociais em âmbito mundial, em fins dos anos 1960, colocou a gestão fordista também em condições delicadas (Bruno, 1996).

Todos esses aspectos levaram as corporações empresariais a explorarem experiências alternativas de organização, até então restritas a locais específicos, como as cadeias de pequenas firmas estruturadas sob a chamada Especialização Flexível, na Terceira Itália (Cattani, 1999), ou no plano interno dos processos de trabalho nas plantas, os Grupos Semiautônomos, organização desenvolvida na Suécia, região de Kalmar, em especial nas fábricas da Volvo e Saab-Scania (Fleury; Vargas, 1983). A mais ousada experiência, entretanto, tendo mais uma vez como berço a indústria automotiva, foi desenvolvida no Japão a partir dos anos 1950 sob a coordenação de Taiichi Ohno, engenheiro industrial da Toyota Motor Company.

Tal como no taylorismo-fordismo, não se tratou de ensaios isolados de métodos de gestão do trabalho e de relações entre firmas nas cadeias produtivas: um contexto mais amplo embasou tais experiências. Diferentemente dos EUA, onde abundavam matérias-primas e mercado consumidor, as condições enfrentadas pelo Japão no pós-1945 exigiram de suas empresas atenderem a um mercado interno fechado e com uma demanda gradual e diversificada (Coriat, 1994; Posthuma, 1997). Além disso, independentemen-

${ }^{4}$ Proliferava, inclusive, um forte destaque aos fatores "psicológicos" e sua relação com a produtividade, como nos estudos de Maslow, de Argyris, de Herzberg e, posteriormente, na chamada Escola Sócio-Técnica (Fleury; Vargas, 1983). te do protecionismo estatal em face do comércio exterior, as empresas japonesas, ao contrário das ocidentais, sempre foram fortemente integradas por uma forma de propriedade em que diferentes grupos se reúnem como "famílias", os zaibatsu, dividindo entre si a posição de acionistas majoritários em negócios comuns. A própria Toyota é exemplar nesse aspecto. ${ }^{5}$

O sistema toyotista permitiu, assim, a configuração de uma rede de subcontratação entre empresas muito mais forte, que, no caso da Terceira Itália e justamente sobre essa base, conseguiu fundamentar um método de produção e entrega mais rápido e preciso que os preexistentes - o just in time/kan ban ${ }^{6}$-, uma vez que a rede de empresas toyotista se fortalece pela focalização das firmas no núcleo principal dos seus negócios, gerando desverticalização e terceirização. Como parte desses elementos, a intensificação do uso da força de trabalho foi fundamental, mediante o desenho de uma organização dos processos de trabalho que atribui a cada trabalhador uma gama diversificada de tarefas até então apartadas pela introdução do taylorismo-fordismo - como, por exemplo, no caso de uma empresa metalúrgica, o controle da qualidade dos produtos ou serviços junto da execução; a manutenção e limpeza das instalações após o seu uso; a operação simultânea de vários equipamentos; entre outros. (Antunes, 1995; Castro, 1995; Coriat, 1993, 1994; Gounet, 1999; Ohno,

${ }^{5}$ Não há, na diretoria da Toyota, membros que não sejam antigos da empresa e eles, na maioria, advêm da família proprietária original. A maior fatia das ações que dispõe ao público pertence a empresas relacionadas aos seus negócios, das quais, reciprocamente, a Toyota também adquire cotas, de modo que as partes não medem seus retornos apenas na forma de dividendos, mas "a propriedade é usada como símbolo de um relacionamento, em que os 'ganhos' provenientes da obrigação comum, implícita, vêm de um trabalho conjunto." (Keller, 1994, p. 141; Conceição, 2001).

${ }^{6}$ Segundo Sayer (1986), ao invés de se produzirem grandes volumes, antecipando-se à demanda, a essência do just in time consiste na realização do trabalho na quantidade e no tempo estritamente necessários. Os estoques são reduzidos e adicionados em ordem para substituir partes removidas a jusante da linha de produção. Assim, os postos, ao término da linha, recebem instruções de produção que, repassadas aos demais trabalhadores imediatamente linha acima (e assim sucessivamente), exigem que cada um inicie a produção designada. Essas comunicações podem ser efetuadas através de etiquetas chamadas "kan ban", passadas ao trabalhador linha acima, quando exigido (Curry,1993). 
1997; Posthuma, 1997; Silva, 1991). ${ }^{7}$

Tais características produtivas adequavamse perfeitamente à conjuntura econômica de baixo crescimento e instabilidade cambial advinda da crise dos anos 1970 e, uma vez acelerada a abertura das fronteiras comerciais nacionais a partir dos anos 1980, a difusão do toyotismo foi relativamente rápida, ${ }^{8}$ tendo à frente a indústria automotiva, mesmo porque o maior mercado do ramo no mundo, os EUA, já havia sido invadido, nessa época, pelos japoneses. (Amin; Malmberg, 1994; Hiraoka, 1989; Garrahan; Stewart, 1994; Rachid, 1994; Womack; Jones; Roos, 1992).

A indústria automotiva ocidental reagiu com uma súbita automatização, sem muitos resultados. Num segundo momento, organizou suas plantas, buscando fórmulas de gestão mais "flexíveis", obtendo um relativo sucesso, pois, embora modelos assim também emergissem em regiões ocidentais específicas, suas adaptações às gigantescas plantas tayloristas-fordistas exigiam mudanças nem sempre possíveis no curto prazo. Num terceiro passo, contudo, as corporações estadunidenses e europeias perceberam que compunham a maior rede de empresas automotivas com plantas instaladas no mundo. A partir daí, encontraram uma saída, novamente por meio de sua hegemonia no âmbito dos Estados nacionais: amparadas na lenta abertura comercial iniciada na década de 1980 em quase todos os países capitalistas (pela qual buscavam equilibrar as tendências oscilatórias do câmbio e dos balanços de pagamento), engendraram as estratégias denominadas global sourcing e follow sourcing.

Designa-se global sourcing a estratégia pela qual as montadoras realizam uma cotação internaci-

${ }^{7}$ Para uma síntese desses estudos, consultar Pinto (2010a).

${ }^{8}$ No caso do Brasil, tal difusão tem sido verificada desde o final dos anos 1980, mas, sobretudo, após a década de 1990 , em especial nas indústrias metalúrgicas avançadas, mas também nos setores químico-petroquímico, têxtil, calçadista, e nos setores de servicos dos bancos e das telecomunicacões às artes. Ver, sobre todos esses setores (Antunes, 2006). Há mais estudos sobre o tema, como: Abreu e colaboradores (2000); Alves (2000); Araújo, Cartoni e Justo (2001); Bedê (1996); Carvalho e Schmitz (1990); Ferreira (1993); Gitahy e Rabelo (1991); Humphrey (1993, 1994); Pochmann e Santos (1996); Posthuma (1995, 1997); Rabelo (1994); Rachid (1994, 2000); Rosandiski (1996); Salerno (1985, 1993); Salerno e colaboradores (2002). onal de fornecedores, levando-se em conta, nessa ordem de fatores: $\left(1^{\circ}\right)$ os preços; $\left(2^{\circ}\right)$ a qualidade exigida para cada tipo de artigo; $\left(3^{\circ}\right)$ os prazos de entrega. Feito isso, as montadoras definem, dentre as empresas cotadas, seus principais fornecedores. Como não se aplica essa estratégia a elementos críticos dos veículos, evitando-se, assim, riscos inerentes ao transporte das peças ou alterações inesperadas nos padrões de qualidade, o global sourcing se limita geralmente a produtos de baixa agregação tecnológica, a fim de que possam ser rapidamente substituídos os fornecedores escolhidos por outros, em caso de problemas.

Quanto aos segmentos de autopeças de alta criticidade e agregação tecnológica (os chamados subconjuntos ou "sistemas"), ${ }^{9}$ sua produção evidentemente exige dos fornecedores maior confiabilidade. As montadoras passaram, então, a estabelecer um tipo de relação mais próxima, não necessariamente em termos geográficos, mas no sentido de se levar em conta uma outra ordem de fatores: $\left(1^{\circ}\right)$ qualidade exigida para cada tipo de artigo; $\left(2^{\circ}\right)$ prazos de entrega; $\left(3^{\circ}\right)$ preços. Os contratos com os fornecedores passaram a incluir, nesses segmentos, o fornecimento por um período determinado de tempo (como a vigência do veículo no mercado), o estabelecimento de metas comuns de qualidade e produtividade, e, por fim, a capacidade de os fornecedores desenvolverem, em parceria com as montadoras, projetos de subconjuntos dos veículos. Trata-se, aqui, da estratégia chamada de follow sourcing. ${ }^{10}$

Enquanto o global sourcing pulveriza a concorrência, distanciando os fornecedores da concepção dos veículos, tornando-os dependentes das montadoras e lançando-os em uma rede de incertezas, na qual usualmente quem ganha o contrato é quem consegue rebaixar ao máximo o seu preço em nível mundial, o follow sourcing, por outro lado, permite a edificação de uma cadeia de

${ }^{9}$ Componentes que agregam em si, como módulos completos, funções básicas dos veículos, por exemplo: painel de instrumentos, injeção eletrônica, freios, direção, suspensão, transmissão, entre outras partes de grande complexidade tecnológica.

${ }^{10}$ Sobre as estratégias de global sourcing e follow sourcing, ver maiores detalhes em Costa e Queiroz (1998). 
empresas fornecedoras mais independentes das montadoras - no sentido do desenvolvimento de sua própria tecnologia. Surgem as chamadas "sistemistas", empresas especializadas de médio e grande porte que participam diretamente dos projetos dos veículos e que reúnem, em torno de si, uma estrutura também hierarquizada de fornecimento por outras empresas (Salerno et al., 2002).

Deve-se perceber, nesse ponto, que, apesar de distintas, o global sourcing e o follow sourcing compõem, na verdade, estratégias complementares de maximização da qualidade e redução de preços e deficiências de entrega. Aliás, além de serem utilizadas de forma combinada, o seu uso não somente está restrito às montadoras, mas abrange também as próprias empresas de autopeças, principalmente as sistemistas, que as empregam junto aos seus fornecedores de insumos, pois tanto as plantas montadoras como as de autopeças configuram, cada qual, redes de microcadeias de produção e fornecimento, congregando vários negócios e operações produtivas e de serviços em uma relação tempo-espacial densa e intrincada, num ritmo crescente de fusões, aquisições, parcerias, contratos de fornecimento condominiais ou a longa distância etc.

A combinação dessas duas estratégias permitiu à indústria automotiva ocidental acelerar o lançamento de novos produtos nos mais diversos lugares, sem que, para isso, tivesse de desenvolver localmente toda a produção dos artigos novos: surgiram as plataformas globais, ${ }^{11}$ visando a obter vantagens, como a tecnologia avançada nos países centrais, matérias-primas e força de trabalho de baixo custo na periferia (Amin; Malmberg (1994), Amin; Smith, 1990; Conceição, 2001; Costa; Queiroz, 1998; Gereffi, 1996). Como parte integrante desse processo, contudo, a indústria de autopeças dos países periféricos foi rapidamente absorvida por grupos estadunidenses, europeus e japoneses. Incapazes

${ }^{11}$ Veículos projetados para serem feitos e consumidos em diversas partes do mundo, como, por exemplo, o Fiat Palio, projetado para ser montado, ao mesmo tempo, na $\mathrm{Ar}$ gentina, Colômbia, Venezuela, Marrocos, Índia, China e no Brasil - onde foi lançado em meados da década de 1990, produzido, no entanto, com peças importadas da Venezuela, Marrocos, Equador, Egito, Argélia e Vietnã (Conceição, 2001). de atingir as escalas e preços (agora cotados em nível internacional), intimidados diante dos riscos e custos de uma produção flexível e tecnologicamente avançada, sucumbiram a fusões e aquisições que ampliaram a concentração de capital nesse ramo. (Costa; Queiroz, 1998; Conceição, 2001; Laplane; Sarti, 1995; Pinto, 2006; Posthuma, 1997). Amparando de perto essa tendência, as montadoras cortaram em cerca de $2 / 3$ o número de suas fornecedoras de autopeças, priorizando os sobreviventes obviamente, as coporações transnacionais - que, por sua vez, intensificaram ainda mais o enxugamento e a terceirização de atividades em todos os países onde mantêm operações. ${ }^{12}$

Sob tais condições, foram introduzidas, nessas plantas filiais, uma gama de elementos da gestão flexível da força de trabalho, tendo por orientação a metodologia do Sistema Toyota de Produção - com diferenças e adaptações locais. Como exemplo concreto, adentraremos, na próxima seção, na análise das informações que obtivemos no estudo de caso que realizamos na planta de uma empresa sistemista transnacional do setor de autopeças entre 2005-2006. Advertimos que, com o fim de preservar as fontes de informação, usaremos aqui nomes fictícios tanto para os entrevistados cujas falas serão citadas, quanto para a própria empresa. Assim, a planta subsidiária por nós analisada será denominada de American Company do Brasil. O mesmo se aplica à matriz e às demais instâncias do grupo oligopólico em nível internacional (American Company Division, Northern Equipaments Division, Northern Space Division e Northern Group Inc.), citadas logo a seguir.

\section{A GESTÃO FLEXÍVEL TOYOTISTA E A MERCANTILIZAÇÃO NAS RELAÇÕES DE TRABALHO}

A American Company do Brasil é uma das quinze plantas filiais, distribuídas por oito

${ }^{12}$ A respeito dessas mudanças na estrutura de fornecimento da cadeia automotiva, difundidas com maior vigor a partir da década de 1980(Hoffman; Kaplinsky, 1987; Garrahan; Stewart,1994; Babson,1995. 
países, da American Company Division, a qual, junto da Northern Equipaments Division e da Northern Space Division, forma as três divisões do Northern Group Inc., grupo estadunidense fundado em 1857 e voltado para a manufatura de estruturas e componentes metálicos de precisão. A Northern Equipaments Division atua no setor de bens de capital e a Northern Space Division, no de aeronaves comerciais e militares. Mas a American Company Division, que representa sozinha $40 \%$ do negócio do grupo, é uma das maiores fabricantes mundiais de estampados e molas de precisão, entre outros componentes voltados para a linha automotiva, a linha branca e o setor de bens de capital (American Company do Brasil, 2005; Northern Group INC., 2005).

O Northern Group possui um presidente geral, que ocupa o topo da pirâmide de comando, abaixo do qual há três vice-presidentes, sendo cada um o presidente de uma das três divisões acima citadas. Para o presidente da American Company Division, reportam-se general managers, cada qual responsável por três unidades produtivas no mundo. No nosso caso, a planta de Campinas é representada por um desses general managers, junto das unidades do México e Canadá. Abaixo dos general managers, estão os diretores gerais das plantas, e, depois deles, os gerentes de áreas de cada uma delas.

Aqui há uma cisão. Enquanto os gerentes das áreas de Vendas, de Engenharia e Desenvolvimento, de Qualidade e de Produção das plantas respondem diretamente aos diretores gerais, os gerentes das áreas de Controladoria e de Recursos Humanos, embora devam também se reportar hierarquicamente ao diretor geral da planta no país, devem prestar informações e encaminhar relatórios regularmente a diretores mundiais de Controladoria e de Recursos Humanos da American Company Division, nos EUA, os quais, por seu turno, responsabilizam-se pelo andamento dessas áreas no plano mundial da matriz, reportando-se a vice-presidentes de Recursos Humanos e de Controladoria Geral do Northern Group.

Essas exceções são significativas, pois atra- vés delas, podemos observar os graus de autonomia e de dependência das plantas em face das políticas mundiais da American Company Division e do Northern Group. Na Controladoria, as conexões diretas entre as gerências locais e a rede de diretores e vice-presidentes mundiais (da American Company Division e do Northern Group) têm como objetivo dinamizar o fluxo de informações e permitir análises rápidas sobre as finanças de cada planta, em termos de suas capacidades e necessidades de investimentos, funcionando como suporte às decisões locais das plantas, regionais da matriz e mundiais do Northern Group. É o "coração" financeiro da corporação e suas “veias”. Por isso, há a necessidade de uma centralização do comando. O caso dos Recursos Humanos é ainda mais interessante, pois, embora ele esteja configurado da mesma forma, com um comando centralizado ligando fortemente as filiais à matriz e essa ao grupo, sua função é menos a de suporte e muito mais a de implantação de diretrizes. É o “cérebro” da corporação e seus "nervos", a interligar cada cabeça, numa filosofia comum em várias partes do mundo, pois de nada adiantaria uma empresa ter solidez financeira se não dispusesse de uma coesão ideológica do topo à base da sua hierarquia de trabalho.

Perfazendo exatamente essa ordem, no topo da corporação há um conjunto de políticas básicas dessa área que partem do Northern Group, através do seu vice-presidente em Recursos Humanos, para todas as empresas, entre elas a American Company Division. Num segundo âmbito, as decisões são tomadas pelo diretor mundial de Recursos Humanos da American Company Division, cujas determinações seguem políticas do Northern Group, mas acrescidas de critérios específicos, cabendo, então, à matriz e às filiais segui-las. O terceiro âmbito é o circunscrito à legislação trabalhista dos países onde estão as plantas filiais, onde muitas vezes há a necessidade de adaptação das políticas vindas do Northern Group e da American Company Division aos contextos locais. Abaixo desses três âmbitos de decisão, há uma gama de políticas internas da própria gerência de Recursos Humanos das unidades filiais e que, embora con- 
tenham decisões estratégicas da matriz dirigidas a países como o Brasil, são determinadas pelo gerente de Recursos Humanos da planta, com o aval do diretor geral, sendo facultado ao último implementar modificações, desde que dentro da hierarquia acima exposta. É o âmbito máximo da autonomia das plantas filiais, ainda que, segundo o gerente de Recursos Humanos da unidade de Campinas, seja uma autonomia que deva consolidar um controle que permanece centralizado no Northern Group.

Se, tanto num caso como noutro, o comando central é flexibilizado à medida que descemos na hierarquia de decisões das plantas matrizes às filiais, essa flexibilização, nos Recursos Humanos, está diretamente ligada aos cargos e funções a que estão submetidos os assalariados da empresa, da seguinte forma: nas esferas operacionais, é reservada uma parte muito maior de controle às gerências da matriz e das filiais, enquanto nas esferas administrativas, o controle é mais centralizado nas políticas do Northern Group. Um exemplo é o aumento salarial: enquanto, nas esferas operacionais, seguem-se as campanhas e acordos coletivos de cada categoria e país onde estão as plantas, nas esferas administrativas, tais aumentos devem ocorrer uma vez ao ano e em abril, mediante uma avaliação feita pelas plantas, segundo critérios rígidos do Northern Group. Outro exemplo, ainda mais forte, são os requisitos mínimos, dados pelo Northern Group, para a contratação e promoção nos cargos diretamente ligados aos diretores gerais das plantas, como os gerentes de Recursos Humanos, de Controladoria, de Vendas, de Engenharia e Desenvolvimento, de Produção e de Qualidade. Não é demais aludir aqui ao fato de que, entre esses requisitos mínimos, está a fluência no idioma inglês.

Essa corporação transnacional produz, portanto, uma diferenciação entre os seus assalariados, compondo, na sua esfera administrativa, um grupo de trabalhadores que, apesar de não possuir as mesmas condições de vida nos diferentes países em que se localiza, éregido por regras estabelecidas num centro de decisão situado nos EUA. Isso é, sem dúvida, uma forma de controle e, mais propriamente, de construção de consentimento entre os trabalhadores dos níveis gerenciais, através de um mecanismo que fortalece a coesão de interesses, no plano global, entre as matrizes (Divisões), as filiais e os detentores do capital, ou seja, os acionistas majoritários do Northern Group.

Somente sob essa forte rede de controle mundial, centralizada no topo da corporação, é que a gestão da força de trabalho foi, nos níveis operacionais, delegada às gerências de Recursos Humanos locais. Similarmente, as inovações tecnológicas na produção, os estudos de mercado, as atividades de Pesquisa e Desenvolvimento (P\&D) e o controle das finanças locais ficam a cargo das gerências de Produção e de Qualidade, de Vendas, de Engenharia e Desenvolvimento e de Controladoria das plantas. Todas essas áreas funcionam como "correias de transmissão" dos objetivos do Northern Group em sua expansão mundial e, apesar da autonomia local de que dispõem, seus assalariados passam pelo crivo de contratações, treinamentos e avaliações minuciosamente preparados pelas diretorias mundiais e vice-presidências da American Company Division e do Northern Group.

Esse controle centralizado fica evidente nas falas dos gerentes entrevistados na planta de Campinas. Em quase todos os assuntos sobre os quais indagamos, suas respostas, como nos exemplos a seguir, foram dadas na primeira pessoa, no singular ou no plural, como se fossem eles mesmos a corporação ou seus proprietários (os grifos são nossos):

Na manutenção, eu só tenho um supervisor [...]. A limpeza que eu tenho dentro da fábrica [...]. Eu tenho um líder que está fazendo engenharia [...]. Esse produto, no caso, ele já sai da nossa máquina para a linha de montagem do cliente. ${ }^{13}$

Que estrutura eu vou ter que ter aqui dentro? Vou ter que investir em novas linhas de produção, em equipamentos? Esse investimento pode ser muito alto e eu não vou ter o retorno esperado

${ }^{13}$ RIBEIRO, Jorge. Depoimento [entrevista realizada com o gerente de Recursos Humanos]. (Pinto, 2011, p. 81). 
[...]. Então, infelizmente eu tenho que manter na Brasimet de São Paulo [...]. A qualidade é primordial para que eu homologue um fornecedor $[\ldots]{ }^{14}$

Bom, na nossa empresa [planta de Campinas], o nosso principal marketing é justamente a capacitação tecnológica [...]. Nós sabemos lidar com os problemas, sabemos lidar com coisas difíceis e que exijam responsabilidade, por isso nós temos tecnologia e conhecimento técnico [...]. $E u$ não lanço um produto em si. Eu penso num processo, num novo material, pois o produto, em si, ele tem que ser casado com a necessidade do cliente. ${ }^{15}$

Para além desse discurso internalizado, cabenos verificar como tais gerências assalariadas, com sua autonomia local, estruturam as plantas a fim de manterem altas taxas de acumulação de capital, dentro das metas postas pelos detentores dos meios de produção no exterior.

Entre 1989 e 1990, em meio à crise provocada pela abertura comercial e todos os ajustes recessivos internos do governo Collor, a gerência de Recursos Humanos da planta de Campinas terceirizou todas as atividades da esfera de apoio - ou seja, a manutenção elétrica, mecânica e predial, a limpeza e a segurança da fábrica. Em 1998, iniciou-se o kaizen, um sistema de análise constante dos processos de trabalho, feito por uma equipe multidisciplinar, na qual são envolvidos trabalhadores desde os níveis operacionais até os gerenciais e cuja finalidade é aprimorar a ergonomia do trabalho, melhorar o controle de qualidade e aumentar a produtividade, eliminando o tempo perdido entre operações e "liberando" força de trabalho para outros setores.

Perfazendo um importante instrumento de aproximação entre as gerências e os níveis operacionais, o kaizen abre um canal de extração do conhecimento tácito que os trabalhadores acumulam sobre os processos de trabalho em que se inserem, mediante sugestões de melhorias que fazem e que acabam se consolidando em projetos de grande envergadura para a empresa. Como exemplo, até 1998, a planta de Campinas dividia-se em áreas

${ }^{14}$ RAMOS, Vitor. Depoimento [entrevista realizada com o gerente de Melhoria Contínua]. (Pinto, 2011, p. 81).

${ }^{15}$ MELLO, Lucas. Depoimento [entrevista realizada como o gerente de Engenharia e Desenvolvimento]. (Pinto, 2011, p. 81. com equipamentos semelhantes, dedicados e conduzidos por trabalhadores especializados. Com o kaizen, os operários, em ensaios coordenados pelas gerências, introduziram dispositivos de segurança e de funcionamento automáticos nos equipamentos (a chamada “autonomação"), ${ }^{16}$ simplificando o seu manuseio e permitindo que fossem operados por trabalhadores não necessariamente especializados e, inclusive, em menor número. Tais equipamentos foram dispostos de modo a configurar "células de trabalho”, que, por sua vez, também foram arranjadas de acordo com os itens que fabricam, concentrando, num menor espaço, processos complementares e diminuindo, com isso, o translado de pessoas e materiais.

Já se pode notar como o kaizen, além de corresponsabilizar os operários na organização do trabalho na empresa, produziu outros três resultados: (1) a criação de aparatos automatizados reduziu as interrupções da produção por quebra de máquinas “dedicadas", pois os trabalhadores nelas ocupados são transferidos rapidamente a outros equipamentos nessa eventualidade, uma vez que o seu manuseio foi facilitado pelos novos dispositivos de segurança e funcionamento automáticos; (2) por intermédio dessa automação, a organização da produção em células tornou mais evidente às gerências o andamento de cada pedido e os estoques de materiais em processo, possibilitando, assim, uma eliminação contínua dos chamados "poros" das jornadas de trabalho; (3) o layout celular, por sua vez, ao aglutinar processos complementares e reduzir o translado de produtos intermediários no interior da produção, evitou as ocorrências de mistura de peças entre lotes diferentes, gerando uma enorme economia da força de trabalho antes empregada na conferência de tais lotes.

Posteriormente, as células, dispondo dessa crescente polivalência dos operários, passaram a se reacomodar constantemente, aglomerando, em si, ora mais, ora menos equipamentos, de um e de outro tipo, obrigando, assim, os trabalhadores a se ${ }^{16}$ Definição presente em Coriat (1994), advinda da fusão
das palavras "autonomia" e "automação". 
adaptarem rapidamente a esse rearranjo contínuo, que varia de acordo com as demandas dos segmentos de mercado em que a empresa atua (a disposição entre as várias células, de fato, mudou várias vezes ao longo da nossa pesquisa de campo, conforme a empresa absorvia ou dispensava negócios). Por fim, os operários passaram a ser treinados no uso de medidores e na elaboração de cartas de Controle Estatístico de Processo (CEP), responsabilizando-se totalmente pela qualidade do que produzem em cada operação, com o que se reduziu o trabalho de restauração de itens defeituosos. Um dos operadores-ajustadores que entrevistamos nos disse, acerca da sua jornada diária de trabalho:

Para falar a verdade, eu trabalho no setor inteiro de estamparia. São divididas em 'Ralo', 'Peixe', 'Água', 'Cofap' e 'Lingueta', cinco células, cada uma faz um produto. Só que eu trabalho em todas. Ajusto [a ferramenta na máquina], ponho para operar e libero o produto. E têm as inspeções [de qualidade], vamos supor, a cada dez mil [peças produzidas]. Depois precisamos preparar a próxima ferramenta, o próximo material: os desbobinadores lá são duplos; esse lado está trabalhando, e desse lado você tem que estar arrumando a outra [máquina]. A gente faz manutenção participativa também, para lubrificar, ver se tem algum defeito. E faz a limpeza semanal, que é na sexta-feira, em todo o local de trabalho, na máquina e no chão. ${ }^{17}$

Trata-se de um processo que atinge não

${ }^{17}$ PEDRO, Luiz. Depoimento [entrevista realizada com trabalhador da esfera da Produção]. Pinto (2011, p. 85).

${ }^{18}$ MUNHOZ, Walter. Depoimento [entrevista realizada como o gerente de Produção]. Pinto (2011, p. 90).
Já abordamos, em outros trabalhos, ${ }^{19}$ como o tripé "autonomação, celularização e polivalência", ao invés de uma "visão global da empresa", produz, na realidade, a aglutinação de um grande número de tarefas simplificadas numa quantidade menor de postos de trabalho, gerando uma exploração extensiva e intensiva maior do que no sistema taylorista-fordista, inclusive pela ausência de incremento salarial em face das novas atribuições assumidas pelos trabalhadores e, ademais, pelo abuso de horas extras que esses sistemas flexíveis de gestão do trabalho requerem. Nosso objetivo, aqui, será mostrar, no entanto, como tais sistemas, em especial o toyotista e sua ocidentalização, promovem uma espécie de "mercantilização" das relações entre os assalariados no interior das empresas. Tomemos, como uma referência, o Quadro 1.

Como o próprio título aponta, esse quadro foi aplicado visando a captar a importância de alguns critérios na contratação de trabalhadores para a esfera da produção da empresa. ${ }^{20}$ No entanto, segundo o gerente de Recursos Humanos que o preencheu, tecendo-nos, ao mesmo tempo, comentários -, ele também é representativo dos casos de contratação em todas as demais esferas e, inclusive, dos casos de promoções no mercado interno de trabalho da empresa. Mas há particularidades em cada um desses casos.

Vê-se que a escolaridade, a formação e a experiência profissional ${ }^{21}$ compõem os três aspectos mais importantes em uma contratação. Todavia, na opinião da gerência de Recursos Huma-

${ }^{19}$ Em textos sucintos como Pinto (2008, 2009, 2010b); ou, de modo mais aprofundado, em Pinto (2011).

${ }^{20}$ Nesta pesquisa, compreende-se por esfera da produção o conjunto de processos de trabalho diretamente relacionados à fabricação dos produtos, desde abastecimento de matériasprimas nas máquinas e sua transformação, passando pela confecção das ferramentas, manutenção da maquinaria e instalações fabris, até o controle de qualidade dos produtos e seu empacotamento final (Pinto, 2011, p. 165).

${ }^{21}$ Compreendemos por "experiência profissional" o conhecimento tácito desenvolvido espontaneamente pelo trabalhador no contínuo exercício do labor e quase sempre compartilhado (formalmente ou não) entre os colegas de trabalho. Já por "formação profissional" compreendemos os treinamentos de caráter técnico e voltados a uma atividade especializada, realizados dentro e fora das empresas pelos trabalhadores, bem como os cursos de formação tecnológica (nível médio e superior), de graduação e pós-graduação que possuem (e aqui nos referimos 


\begin{tabular}{l|c}
$\begin{array}{c}\text { Quadro } 1 \text { - Critérios de qualificação na contratação de trabalhadores } \\
\text { para a esfera da produção - American Company do } \\
\text { Brasil - 2005 }\end{array} \begin{array}{l}\text { Critérios } \\
\text { de qualificação }\end{array}$ & $\begin{array}{c}\text { Importância segundo a gerência de } \\
\text { Recursos Humanos } \\
(1=\text { mínima; } 5=\text { máxima })\end{array}$ \\
\hline Nível de escolaridade & 5 \\
Formação profissional & 5 \\
Experiência profissional & 5 \\
Disponibilidade para turnos diferenciados & 4 \\
Aprovação em testes de seleção da empresa & 3 \\
Objetivos de carreira & 2 \\
Constituição física & 2 \\
Origem social & 1 \\
Idade & 1 \\
Sexo & 1 \\
Temperamento e disposição adequados & 1 \\
\hline Fonte: Pinto (2011, p. 173) &
\end{tabular}

nos, embora esses três itens sejam imprescindíveis em uma contratação, não são os únicos a serem requisitados nas promoções - ou seja, no âmbito do mercado interno de trabalho da planta. Nesse âmbito, levam-se em conta critérios intangíveis, ou "fluidos", como certos perfis comportamentais expressos em situações cotidianas de trabalho. Critérios que, diferentemente da "rigidez" presente na escolaridade, na formação e na experiência profissional, não se oferecem à mensuração ou à observação conjunta pelas gerências e trabalhadores em experiências controladas. Não obstante, são tais critérios determinantes nas promoções, conforme atestam as próprias palavras do gerente de Recursos Humanos:

Nós temos hoje um supervisor na parte de estampados, o Pedrinho: ele entrou como aprendiz.

Hoje está como supervisor, pois está fazendo engenharia - para ser supervisor, tem de estar fazendo engenharia [aspecto rígido], porque nós precisamos de engenheiros lá embaixo [no chão de fábrica]; ele está fazendo engenharia no momento, mas, antes dele começar a cursar, ele já tinha sido promovido, porque ele é um cara acima da média, se destacou muito [aspecto fluido].

Por exemplo, surgiu uma vaga de ajustador, sei lá, em prensa, que é o exemplo que nós temos usado, eu vou fazer uma avaliação, uma análise de

ao peso que a área de formação nesses cursos tem para o trabalho a ser desenvolvido na empresa, segundo a gerência entrevistada; portanto, não apenas a escolaridade em si, cuja importância foi tomada separadamente). quantas pessoas eu tenho com possibilidade para ocupar esse cargo. Eu levanto cinco pessoas. Aí a gente vai ver: 'O João: tem escolaridade?' Tem. 'Tem curso técnico?' Tem. 'Tem experiência?' [aspectos rígidos]. Não tem. Então, já segura. Até que você vai achar um que tenha todos os quesitos, aí você vai partir para a personalidade dele [aspecto fluido]: como que é o João, como que é o José, como que é o Manoel e tal. Aí você vai definir:'Ah, não, olha, acho que aqui nesse cargo, nessa situação, a melhor situação é o José’. Aí, o José é promovido.

Incide na avaliação geral do funcionário o comportamento pessoal dele, a postura, como que ele vê a empresa, como os outros veem ele dentro da empresa, qual é a visão que o gerente dele tem dele, dos outros gerentes, qual que é a visão do RH. Principalmente pesa a visão do gerente dele, do RH e do diretor geral [todos aspectos fluidos], e aí os atributos técnicos, a formação dele, a experiência [aspectos rígidos], é um somatório de todos os fatores. ${ }^{22}$

Mesmo se nos restringirmos aos casos de contratação, tomando critérios como a "Aprovação em testes de seleção da empresa" (terceiro lugar em importância no Quadro 1), iremos nos deparar, novamente, com a fluidez dos perfis comportamentais. Segundo a gerência de Recursos Humanos, havia roteiros prescritos para esses testes, os quais foram abolidos no início da década de 1990, seja por demandarem pessoas para aplicá-los - o que os tornou inviáveis com o quadro cada vez mais enxuto da planta -, seja pela ocorrência de casos de candidatos que se saíam bem nos testes, mas não no dia a dia, tendo também ocorrido o inverso: ficavam nervosos e se saíam mal nos testes, embora fossem excelentes profissionais. Sendo assim, a referida gerência optou por testes mais práticos:

O 'teste' é: o supervisor leva o pretenso candidato a funcionário lá na máquina e fala: 'Esta máquina aqui, você conhece? Se formos fazer isso, faria o quê? E aquilo? Você acha que dá para trabalhar aqui? Etc.' Então, nós preferimos ter esse feeling de quem conhece a máquina e, eventualmente, o

${ }^{22}$ Os três parágrafos acima foram extraídos da entrevista realizada como o gerente de Recursos Humanos, representado pelo nome fictício de Jorge Ribeiro (Pinto, 2011, p. 101). 
supervisor pode pedir a ajuda de um ajustador mais antigo, de um líder, para fazer um batebola ali com o candidato. ${ }^{23}$

Deixemos de lado, aqui, a justificativa dos quadros enxutos para entender o "feeling" do dia a dia que o teste tem de revelar. Em primeiro lugar, notemos que esse tipo de teste comporta não somente uma análise da competência técnica do candidato; vai além, pois, mediante a simulação de situações reais, ele abre margem à avaliação de traços comportamentais. Em segundo lugar, os operários efetivos têm, nesse sistema, uma participação mais ativa, o que, se, por um lado, amplia suas ações na divisão do trabalho na empresa, por outro, os responsabiliza com relação ao desempenho futuro dos selecionados, haja vista que as metas de produtividade e qualidade não são mais cobradas pelas supervisões e gerências no âmbito dos postos individuais, mas das células de produção, organizadas internamente e entre si como "times" de novos e antigos operários.

Novamente aqui, transparece, portanto, um controle horizontalizado que se instala entre os próprios trabalhadores, escamoteado pela suposta incorporação de novos saberes e atuações. E, de fato, os antigos operários (segundo pudemos observar em nossas visitas à fábrica) são bastante requisitados não apenas nas seleções, mas no treinamento dos mais jovens, o que os leva a circular cada vez mais entre as células, ampliando, por todo o tecido das relações de trabalho (dos mais jovens aos mais experientes, dos mais especialistas aos mais generalistas), a estratégia da polivalência e retroalimentando, por essa via, o kaizen, a autonomação e os seus resultados já anteriormente comentados.

Voltemos, mais uma vez, ao Quadro 1 e analisemos como o item "Objetivos de carreira" é compreendido pela gerência de Recursos Humanos da American Company do Brasil. Segundo essa gerência, apesar da descrição da estrutura de cargos e salários ser exposta aos candidatos nos processos

${ }^{23}$ Ibid., p. 102. de contratação, a observação do interesse deles na possibilidade de crescimento dentro da empresa não constitui um critério importante nessa ocasião. É, entretanto, um inestimável meio de avaliação do desempenho dos trabalhadores quando se trata de promoções internas:

Se a gente leva isso em consideração como critério de contratação, simplesmente? Não. Mas nós incentivamos as pessoas para que estudem, e não só os cursos que a empresa oferece, mas que façam cursos, que se desenvolvam, para quando surgir a oportunidade estarem preparados. Nós falamos: 'O conhecimento, não é só aqui dentro [da empresa], o conhecimento está dentro da cabeça e, se você vai embora, você o leva'. Queremos que ele [o trabalhador] tenha objetivos de crescimento, de desenvolver uma carreira dentro da empresa. Não queremos contratar uma pessoa que entre hoje, mas que daqui a três meses vá embora, pois estamos investindo. [...] No primeiro mês, ele vai ter um ajustador mais antigo que vai estar acompanhando, o supervisor vai estar mais em cima. Têm os cursos, tem a integração, tem os cursos básicos de qualidade e tudo mais. Então, a gente quer que ele entre e continue trabalhando. ${ }^{24}$

Tanto na unidade brasileira como nas demais, há dois planos de carreira: um para os assalariados mensalistas (que recebem um salário fixado por mês de trabalho) e outro para os horistas (que recebem salário mensalmente, mas fixado por hora trabalhada). A diferença reside nos sistemas de avaliação: para os cargos da esfera administrativa, as avaliações e promoções seguem critérios dos EUA em todas as plantas no mundo - e um critério canônico é jamais promover alguém por tempo de serviço na empresa. Os horistas distribuem-se entre as esferas produtivas e de apoio, embora, para efeito da presente análise, devamos considerá-los apenas como integrantes das primeiras, em vista das atividades de apoio terem sido totalmente terceirizadas (conforme já foi comentado no início) e seus assalariados não serem submetidos aos mesmos critérios que os demais trabalhadores da empresa.

A avaliação dos horistas não é feita "por pares”, ou seja, pelos assalariados na mesma po-

${ }^{24}$ Ibid., loc. cit. 
sição: é uma atribuição dos seus supervisores, apenas. É curiosa a observação do gerente de Recursos Humanos a respeito:

A gente considera que o pessoal horista ainda não tem maturidade suficiente para fazer uma autoavaliação, e isso geraria um dispêndio de tempo muito grande por parte do funcionário, por parte dos supervisores e um resultado que não seria muito efetivo. ${ }^{25}$

De fato, poderia "custar caro" às gerências intervir na lei de bronze do controle horizontalizado da gestão flexível. Afinal, permitir uma avaliação por pares dentro das equipes no interior das células liquidaria com a tão almejada "imparcialidade saudável" nas relações pessoais entre os seus membros, ou seja: a ilusória autorização de um trabalhador em responsabilizar o seu colega de equipe pelo cumprimento das metas gerenciais seria perigosamente dissuadida, emergindo, em seu lugar, uma coletividade potencialmente ofensiva às gerências e que lhes ofuscaria a visão, tirando-lhes, por conseguinte, o poder de ação por vias "fluidas" e obrigando-as a um retrocesso ao inferno taylorista. Por fim, a avaliação por pares liquidaria também com a competitividade entre as células.

As gerências, então, concentram o poder de avaliar e afastam, nessa avaliação, o foco dos postos individuais de trabalho em direção ao âmbito coletivo das células e setores, considerando-os todos como grandes "times" de trabalhadores polivalentes, competitivos e autônomos, não apenas pela assunção de múltiplas tarefas operacionais (mesmo que simplificadas e repetitivas em si), mas pela supervisão restrita dos próprios colegas, com base em índices que abrangem desde o tempo gasto em tarefas cronometradas, falhas e necessidade de retrabalho, chegando-se a indicadores de absenteísmo e até mesmo de acidentes de trabalho.

Em todas as avaliações, tanto para os horistas como para os mensalistas, os avaliados são chamados ao final para discutir os resultados com os

${ }^{25}$ RIBEIRO, Jorge. Depoimento (Pinto, 2007b, p. 208). avaliadores, com vistas a chegarem a um consenso, após o que ambos devem assinar a avaliação. Nas palavras do gerente de Recursos Humanos:

Ele [o avaliador] vai falar: 'Olha, tem um problema aqui que eu estou vendo, sempre no seu departamento tem um problema de devolução, que é um problema de qualidade, então eu vou colocar você para fazer um curso'. Ou então: 'Você tem que melhorar: você já fez três cursos e continua dando problema, o que está acontecendo?' Ou: 'Você é uma pessoa não muito assídua, constantemente eu vejo que você tem faltas'. Ou: 'Olha, a empresa deu dez cursos, ela ofereceu e você fez um: por que você não está fazendo os cursos que a empresa oferece? Algum problema, alguma coisa?'26

Cabe destacar que, durante o processo de avaliação, esses trabalhadores não são confrontados apenas com os colegas e com as gerências: a favor delas e ao lado do apelo ao trabalho mais qualificado e do culto às novas tecnologias, estão as ameaças como os baixíssimos custos dos produtos industrializados de economias capitalistas periféricas como a China. Nas próprias palavras da gerência de Recursos Humanos:

Eu diria para você que, com a globalização, a abertura que houve em 1990, hoje nós não somos mais um fornecedor em nível de Brasil, somos um fornecedor em nível mundial, estamos aptos a fornecer para qualquer empresa em qualquer lugar do mundo. Então, se nós temos capacidade para fazer isso, temos de estar à altura em todos os requisitos: seja em equipamentos, seja em mão de obra, seja quanto às práticas de gerenciamento. Tudo isso tem de estar de acordo com o que se faz lá fora. Porque senão nós começamos a perder mercado, por exemplo, para a China, ou para os Tigres Asiáticos, que têm uma mão de obra superbarata. ${ }^{27}$

Essa preocupação com o emprego, vinculada ao comprometimento com os resultados da empresa no mercado, está expressa, igualmente, na fala dos trabalhadores. Indagado sobre quais foram os objetivos das gerências da American Company do Brasil ao implantarem as técnicas de gestão flexível no trabalho, um operário nos respondeu:

${ }^{26}$ RIBEIRO, Jorge. Depoimento. (Pinto, 2011, p. 103).

${ }^{27}$ Ibid., p. 106. 
Diminuir o quadro de funcionários e o gasto. Para poder vender um produto mais barato e para você se manter no mercado. Não adianta você ter mil funcionários aí e seu rendimento ser pequenininho, se você não consegue vender por um preço bom lá fora [no mercado internacional]. Então, você vai acabar o quê? Vai acabar 'morrendo'. Eu creio que foi um caminho do grupo para se manter no mercado. ${ }^{28}$

Apesar de o atual custo da força de trabalho na indústria automotiva brasileira estar entre os menores do mundo, ${ }^{29}$ as esperanças dos grupos industriais oligopólicos em ampliarem as suas taxas de acumulação de capital locais, pelo que demonstra nosso estudo de caso no setor de autopeças em Campinas, continuam assentadas na fluidez dos componentes comportamentais dos critérios de contratação e promoção de trabalhadores em todas as esferas de trabalho.

Uma fluidez que consolida uma organização do trabalho fundada na polivalência dos trabalhadores, pois, em tudo e por tudo, ela explicita a necessidade, existente na empresa, de um forte comprometimento dos níveis hierárquicos entre si. Explicita também a fluidez crescente da divisão de tarefas nas diferentes esferas, setores e células de trabalho. E, por fim, deixa clara a tão esperada "lealdade", tanto das gerências quanto dos níveis operacionais e, em especial, dos mais jovens, com os objetivos maiores do comando administrativo da empresa nos EUA, ou seja, com a sua acumulação de capital. Uma "lealdade" que deve levar os trabalhadores a se qualificarem por conta própria e a galgarem, a todo custo, postos cada vez mais altos, não necessariamente pela sua escolaridade ou perfil técnico, mas pelo seu perfil pessoal e, sobretudo, político, nas relações que constroem com os demais trabalhadores.

${ }^{28}$ CARLOS, Antônio. Depoimento [entrevista realizada com trabalhador da esfera da Produção]. (Pinto, 2011, p. 107).

${ }^{29}$ A consultoria CSM / Worldwide classifica o mundo da produção automotiva em três níveis de custos: alto, baixo e ultrabaixo. A média do custo da força de trabalho, incluindo benefícios, na indústria automotiva de países como Alemanha, EUA e Japão, é de US\$ 23,00 a US\$ 27,00 por hora. Em regiões como Taiwan e Coreia do Sul, a média cai para US\$10,00 a US\$11,00. O Brasil se enquadra, segundo a consultoria, na terceira categoria, em que a média chega a US\$ 3,00 por hora (Olmos, 2005).

\section{CONSIDERAÇÕES FINAIS}

Com base na análise realizada nas seções anteriores, podemos ousar expor aqui alguns pontos cruciais acerca do sistema de Ohno (o toyotista) e seu grande salto em relação à Ford. Enquanto o pai da indústria de massa, no início do século XX, almejou servilizar o seu corpo de trabalhadores, transformando-os, supostamente, em potenciais consumidores dos seus próprios produtos, o pai da gestão flexível, ao final daquele século, distinguiu-se por tentar servilizálos, transformando-os, supostamente, em potenciais sócios das empresas em que trabalham. Tudo isso, contudo, jamais passou de mera suposição, pois mesmo Ford já contrapunha aos elementos rígidos da gestão do trabalho os elementos fluidos e toda a individualização deles decorrentes no comportamento dos trabalhadores: "vestir a camisa da empresa" foi tão comum em Detroit até meados do século XX, como no ABC paulista, a partir dos anos 1950. ${ }^{30}$

É claro que os tempos que elegeram o sistema de Ohno já eram outros. O capital financeiro e uma nova classe de acionistas poderosos sobrepujaram as gerências industriais. O consumo de massa já não alimentava mais as aristocracias operárias, e o poder do sindicalismo corporativo tampouco contornava a insatisfação dos setores classistas mais combativos ou apresentava soluções aos setores excluídos como os desempregados e precarizados - que, após os anos 1970, proliferaram enormemente. A microeletrônica e a informática acirraram, de forma colossal, a concorrência aberta pela derrubada das muralhas protecionistas nacionais, ao tempo em que os próprios Estados parecem ter sucumbido, junto das burguesias locais que protegiam, frente ao poder de corporações que operam globalmente.

As leis da acumulação de capital têm, portanto, avançado sobre todas as trincheiras que encontram pela frente na vida social. E um fato gritan${ }^{30}$ Ver a respeito do caso estadunidense Gramsci (1990) e do
caso brasileiro Negro (2004), este com suas passagens sobre a "família Willys". 
te é a transposição, cada vez mais clara, de aspectos ora restritos às relações entre as empresas (clientes e suas fornecedoras, matrizes e suas filiais) no plano do comércio globalizado, para as relações entre os próprios assalariados, no plano produtivo local das plantas: da polivalência aos mercados internos de trabalho, percebe-se, hoje, a existência de um mecanismo nas empresas que promove nos trabalhadores uma atitude autoexploratória, em função de uma relação, a acumulação de capital, que, embora os atravesse, paira acima deles.

Tal como sob o sistema taylorista-fordista, os trabalhadores permanecem subsumidos como engrenagens semoventes dessa acumulação de capital, mas num grau de complexidade muito maior, pois não estão subordinados a esse processo por formas coercitivas (físicas ou intelectuais) impostas por uma organização que se lhes defronta objetivamente e com regras frias e racionalistas. Mais do que regras claras, certamente ainda presentes, o que a gestão flexível, em especial a toyotista, impõe aos trabalhadores são transmutações de seus costumes, de suas paixões e de seus caracteres mais profundos, mediante uma introjeção subjetiva de princípios de conduta moral, de um ethos.

Trata-se de um sistema de gestão que constitui, nesse sentido, muito mais do que uma metodologia de organização técnica do trabalho - o grande sonho de Taylor-, mas uma etognosia, estando suas formulações práticas não apenas limitadas a uma forma específica de cooperação no trabalho, mas edificadas na forma de um "governo”, de uma etocracia, na qual tanto operários quanto gerentes assalariados estão servilmente prostrados a um só soberano: o capital.

Texto recebido em 9 de dezembro de 2011 Aceito em 6 de fevereiro de 2012

\section{REFERÊNCIAS}

ABREU, Alice R. et al. Produção flexível e relações interfirmas: a indústria de autopeças em três regiões do Brasil. In: ABREU, Alice R. de P. (Org.). Produção flexível e novas institucionalidades na América Latina. Rio de Janeiro: Ed. da UFRJ, 2000. p. 27-73.

ALVES, Giovanni. O novo (e precário) mundo do trabaIho: reestruturação produtiva e crise do sindicalismo. São Paulo: Boitempo, 2000.

AMERICAN COMPANY DO BRASIL. [Documentos internos da empresa]. Campinas, SP: [s. n.], 2005.

AMIN, A.; MALMBERG, A. Competing structural and instituional influences on the geography of production in Europe. In: AMIN, Ash (Ed.). Post-fordism: a reader. Oxford: Blackwell, 1994.

AMIN, A.; SMITH, I. The British car components industry: leaner and fitter? In: STWERT, Paul; GARRAHAN, Philip; CROWTHER, Stuart (Ed.). Restructuring for economic flexibility. Aldershot: Avebury, 1990.

ANTUNES, Ricardo (Org.). Riqueza e miséria do trabalho no Brasil. São Paulo: Boitempo, 2006.

Adeus ao trabalho? Ensaio sobre as metamorfoses e a centralidade do mundo do trabalho. Campinas: Cortez: UNICAMP, 1995.

ARAÚJO, Ângela M. C.; CARTONI, Daniela M.; JUSTO, Carolina R. D. Mello. Reestruturação produtiva e negociação coletiva nos anos 90. Rev bras. Ci. Soc., São Paulo, v. 16 , n. 45, p. 85-112, fev., 2001. Disponível em: www.scielo.br/pdf/rbcsoc/v16n45/4332.pdf. Acesso em: 9 jan. 2013.

BABSON, S. Lean production and labor: empowerment and explotation. In: BABSON, Steve (Ed.) Lean work empowerment and exploitation in the global industry. Detroit: Wayne State University Press, 1995.

BEDÊ, Marco A. A indústria automobilística no Brasil nos anos 90: proteção efetiva, reestruturação e política industrial. 1996. Tese (Doutorado em Economia) - Faculdade de Economia e Administração, Universidade de São Paulo, São Paulo, 1996.

BRUNO, Lúcia. Educação, qualificação e desenvolvimento econômico. In: . (Org.). Educação e trabalho no capitalismo contemporâneo: leituras selecionadas. São Paulo: Atlas, 1996. p. 91-123.

CARVALHO, Ruy de Q.; SCHMITZ, Hubert. O fordismo está vivo no Brasil. Novos Estudos CEBRAP, São Paulo, n. 27, p. 148-156, jul., 1990

CASTRO, Nadya A. de. Modernização e trabalho no complexo automotivo brasileiro: reestruturacão industrial ou japanização de ocasião? In: . (Org.). A Máquina e o equilibrista: inovações na in đústria automobilística brasileira. Rio de Janeiro: Paz e Terra, 1995.

CATTANI, Antonio D. Trabalho e tecnologia: dicionário crítico. 2. ed. Rio de Janeiro: Petrópolis: Vozes, 1999.

CONCEICÃO, Jefferson José da. As fábricas do ABC no olho do furacão: a indústria de autopeças e a reestruturação da cadeia de produção automotiva nos anos 90. 2001. $224 \mathrm{f}$. Dissertação (Mestrado em Administração) - Centro de Estudos de Aperfeiçoamento e Pós-graduação do Centro Universitário Municipal de São Caetano do Sul, São Caetano do Sul, 2001.

CORIAT, Benjamin. Ohno e a escola japonesa de gestão da produção: um ponto de vista de conjunto. In: HIRATA, Helena S. (Org.). Sobre o "modelo" japonês. automatização, novas formas de organização e de relações de trabalho. São Paulo: EDUSP, 1993. p. 79-91. 
CORIAT, Benjamin. Pensar pelo avesso: o modelo japonês de trabalho e organização. Rio de Janeiro: Revan; Ed. da UFRJ, 1994.

COSTA, Ionara; QUEIROZ, Sérgio. Autopeças no Brasil: mudanças e competitividade na década de noventa. In SIMPÓSIO DE GESTÃOO DA INOVAÇÃ̃O TECNOLÓGICA 20., São Paulo,1998. Anais... p. 1070-1083.

CURRY, James. The flexibility fetish: a review essay on flexible specialisation. Capital \& Class, v. 17, n. 2, p. 99 126, summer, 1993.

DEDECCA, Cláudio S. Reestruturação produtiva e tendências de emprego. In: OLIVEIRA, Marco A. et al. (Org.). Economia \& trabalho: textos básicos. Campinas, UNICAMP 1998. p. 163-186.

FERREIRA, Cândido G. O fordismo, sua crise e o caso brasileiro. Campinas, SP: IE/UNICAMP, 1993. (Cadernos do CESIT, texto no. 13)

FLEURY, Afonso; VARGAS, Nilton. Aspectos conceituais In: . (Coord.). Organização do trabalho: uma abordagem interdisciplinar - sete estudos sobre a realidade brasileira. São Paulo: Atlas, 1983. p. 17-37.

GARRAHAN, P.; STEWART, P. Progress to decline? In: GARRAHAN, Philip (Ed.). Urban change and renewal: the paradox of place. Aldershot: Avebury, 1994.

GEREFFI, Gary. Global commodity chains: news forms of coordination and control among nations and international industries. Competition \& Change, v. 1, n. 4, p. 427-439, 1996.

GITAHY, Leda; RABELO, Flávio. Educação e desenvolvimento tecnológico: o caso da indústria de autopeças. Campinas: DPCT/IG/UNICAMP, 1991. (Texto para discussão, n. 11).

GOUNET, Thomas. Fordismo e toyotismo na civilização do automóvel. São Paulo: Boitempo, 1999.

GRAMSCI, Antonio. Americanismo e fordismo. In: Maquiavel, a política e o estado moderno. 8. ed. $\overline{\text { Rio de }}$ Janeiro: Civilização Brasileira, 1990.

HARVEY, David. A condição pós-moderna. São Paulo: Loyola, 1992.

HIRAOKA, Leslie. Japanese automobile manufacturing in an American setting. Technological Forecasting and Social Change, New York, v. 35, n. 1, p. 29-49, mar., 1989.

HOFFMAN, Kurt; KAPLINSK, Raphel. Driving Force: the global restructuring of technology, labor, and investment in the automobile and components industries. Westview Boulder, 1987.

HUMPHREY, John. "Japanise" methods and the changin position of direct production workers: evidence from Brazil. In: SMITH, Chris et al. (Ed.). Global japanization? the transnational transformation of the labour process London: Routlegde, 1994. p. 327-347.

Adaptando o "modelo japonês" ao Brasil. In: HIRATA, Helena S. (Org.). Sobre o "modelo" japonês: automatização, novas formas de organização e de relações de trabalho. São Paulo: EDUSP, 1993. p. 237-257.

, Maryann. Colisão: GM, Toyota, Volkswagen corrida para dominar o século XXI. Rio de Janeiro: Campus, 1994.

LAPLANE, M. F.; SARTI, F. A reestruturação do setor automobilístico brasileiro nos anos 90. Economia \& Empresa, v. 2, n. 4, out./dez., 1995.

MARINI, Ruy M. Dialéctica de la dependencia. In: América Latina, dependencia y globalización: fundamentos conceptuales. Bogotá: Siglo del Hombre y CLACSO, 2008. p. 107-149. Disponível em: http://bibliotecavirtual.clacso.org.ar/ ar/libros/secret/critico/marini/04dialectica2.pdf. Acesso em 10 jan. 2013.
MARTINS, Carlos E. Globalização, dependência e neoliberalismo na América Latina. São Paulo: Boitempo, 2011.

MATTOSO, Jorge E. L. O novo e inseguro mundo do trabalho nos países avançados. In: OLIVEIRA, Carlos A. et al. (Org.). O mundo do trabalho: crise e mudança no final do século. São Paulo: Scritta, 1994. p. 521-562.

NEGRO, Antonio L. Linhas de montagem: o industrialismo nacional-desenvolvimentista e a sindicalização dos trabalhadores. São Paulo: Boitempo, 2004.

NORTHERN GROUP INC. Annual report to stockholders. Washington: Securities and Exchange Commission, 2005.

OHNO, Taiichi. O sistema Toyota de produção: além da produção em larga escala. Porto Alegre: Bookman, 1997.

OLIVEIRA, Dalila A. A qualidade total na educação: os critérios da economia privada na gestão da escola pública. In: BRUNO, Lúcia (Org.). Educação e trabalho no capitalismo contemporâneo. São Paulo: Atlas, 1996. p. 57-90.

OLMOS, Marli. Mudança no mapa produtivo favorece autopeças do país. Valor Econômico, São Paulo, 29 mar. 2005. (Empresas \& Tecnologia).

PINTO, Geraldo A. A máquina automotiva em suas partes: um estudo das estratégias do capital na indústria de autopeças. São Paulo: Boitempo Editorial, 2011.

A máquina automotiva em suas partes: um estudo das estratégias do capital nas autopeças em Campinas. 2007. 576f. Tese (Doutorado em Sociologia) - Instituto de Filosofia e Ciências Humanas da Universidade Estadual de Campinas, Campinas, SP, 2007b.

. A organização do trabalho no século 20: Taylorismo, Fordismo e Toyotismo. 2. ed. São Paulo: Expressão Popular, 2010a.

Gestão flexível e qualificação operária: sobre a rigi$\overline{\operatorname{dez}} \mathrm{e}$ a fluidez nas relações de trabalho na indústria automotiva do Brasil. In: CONGRESO INTERNACIONAL DE LA ASOCIACIÓN LATINOAMERICANA DE SOCIOLOGIA: latinoamérica interrogada..., 27., 2009, Buenos Aires. Anais eletrônicos... Buenos Aires , 2009.

A maquinaria e manufatura na fábrica flexível: autonomia e heteronomia no trabalho. In: SOUZA, José dos S; ARAÚJO, Renan (Org.). Trabalho, educação e sociabilidade. Marngá: Práxis, 2010b. p. 93-107.

Qualificação e organização flexível do trabalho: elementos para um olhar crítico. Revista Tecnologia e Sociedade, Curitiba, n. 6, p. 49-71.

. Uma abordagem metodológica do tema reestruturação produtiva. Ideias, Campinas, v. 14, p. 149-159, 2007 a.

Uma introdução à indústria automotiva no Brasil. In: ANTUNES, Ricardo (Org.). Riqueza e miséria do trabaIho no Brasil. São Paulo: Boitempo, 2006. p. 77-92.

POCHMANN, M.; SANTOS, A. L. O custo do trabalho e a competitividade internacional. In: MATTOSO, Jorge E.; OLIVEIRA, Carlos A. (Orgs.). Crise e trabalho no Brasil: modernidade ou volta ao passado? 2 ed. São Paulo: Scritta, 1996. p. 189-220.

POSTHUMA, Anne C. Autopeças na encruzilhada: modernização desarticulada e desnacionalização. In: ARBIX, Glauco; ZILBOVICIUS, Mauro (Org.). De JK a FHC: a reinvenção dos carros. São Paulo: Scritta, 1997. p. 389-411.

. Japanese production techniques in Brazilian automobile components firms: a best practice model or basis for adaptation? In: SMITH, Chris et al. (Ed.). Global japanization? the transnational transformation of the labour process. London: Routlegde, 1994. p. 348-377.

. Técnicas japonesas de organização nas empresas de 
autopeças no Brasil. In: CASTRO, Nadya A. de (Org.). A máquina e o equilibrista: inovações na indústria automobilística brasileira. Rio de Janeiro: Paz e Terra, 1995. p. 301-332.

QUADROS, Waldir J. Crise do padrão de desenvolvimento no capitalismo brasileiro: breve histórico e principais características. Campinas: IE/UNICAMP, 1991. (Cadernos do CESIT, textos para discussão n. 6).

RABELO, Flávio M. Qualidade e recursos humanos na indústria brasileira de autopecas. 1994. 237 f. Tese (Doutorado em Economia ) -Instituto de Economia, Universidade Estadual de Campinas, Campinas, 1994.

RACHID, Alessandra. O Brasil imita o Japão? A qualidade em empresas de autopeças. 1992. Dissertação (Mestrado em Política Científica e Tecnologica ) - Departamento de Política Científica e Tecnológica do Instituto de Geociências, Universidade Estadual de Campinas, Campinas, SP, 1994.

Relações entre grandes e pequenas empresas de autopeças: um estudo sobre a difusão de práticas de organização da produção. 2000. f. Tese (Doutorado em Engenharia Mecânica) - Faculdade de Engenharia Mecânica, Universidade Estadual de Campinas, Campinas, 2000.

ROSANDISKI, Eliane Navarro. Reestruturação organizacional: uma avaliação a partir da estrutura do emprego do setor automotivo paulista - 1989-1994.1996. 188f Dissertação (Mestrado em ) - Instituto de Geociências da Universidade Estadual de Campinas, Campinas, SP, 1996.

SADER, Emir; SANTOS, Theotonio (Coord). A América Latina e os desafios da globalização: ensaios dedicados a Ruy Mauro Marini. São Paulo: Boitempo, 2009.
SALERNO, Mário Sérgio et al. A nova configuração da cadeia automotiva brasileira. São Paulo: Escola Politécnica da Universidade de São Paulo, 2002. (Pesquisa desenvolvida junto ao BNDES, pelo Grupo de Estudos em Trabalho, Tecnologia e Organização).

. Modelo japonês, trabalho brasileiro. In: HIRATA, Helena S. (Org.). Sobre o "modelo" japonês: automatização, novas formas de organização e de relações de trabalho. São Paulo: EDUSP, 1993. p. 139-152.

. Produção, trabalho e participação: CCQ e kan-ban numa nova imigração japonesa. In: FLEURY, Maria T.; FISCHER, Rosa M. (Coord.). Processo de trabalho e relações de trabalho no Brasil. 2. ed. São Paulo: Atlas, 1985. p. 179-202.

SAYER, Andrew. New developments in manufacturing: the just-in-time system. Capital $\mathcal{F}$ Class, Londres, n. 30, p. 4372, winter, 1986.

SILVA, Elizabeth B. Refazendo a fábrica fordista: contrastes da indústria automobilística no Brasil e na Grã-Bretanha. São Paulo: Hucitec: FAPESP, 1991.

TAVARES, Maria da C. Ajuste e reestruturação nos países centrais: a modernização conservadora. Economia e Sociedade, Campinas, n. 1, p. 21-57, ago., 1992.

VALENCIA, Adrian Sotelo. El mundo del trabajo en tensión: flexibilidad laboral y fractura social en la década de 2000. Madrid: Plaza y Valdez, 2007.

WOMACK, James P.; JONES, Daniel T.; ROOS, Daniel. A máquina que mudou o mundo. 14. ed. Rio de Janeiro: Campus, 1992. 


\section{TOYOTISM AND THE MERCANTILIZATION OF LABOR IN THE BRAZILIAN AUTOMOTIVE INDUSTRY}

\author{
Geraldo Augusto Pinto
}

The aim of this article is to analyze the advancement of concepts and practices in labor management called "flexible" in the Brazilian automotive industry, particularly those rooted in the Toyota Production System. Through bibliographical research and an empirical case study of a Campinas, SP (Brazil) plant belonging to a transnational group in the auto parts sector, the author shows how changes in the organization of labor were brought about, together with the demand for the workers to have new professional and educational profiles. This analysis conclusively shows how these profiles articulated with management's methods of evaluation in the contracting and promoting processes - have fragmented workers' collectivity in companies, putting monetary value on the relationships that they establish with one another in the workplace since they are based on the introjection and manipulation of their principles of conduct, in the sense of making them subservient to the purpose of accumulation of capital.

KEY wORDs: Toyota Production System. Labor Sociology. Automotive Industry - Brazil.

\section{LE TOYOTISME ET LA MERCANTILISATION DU TRAVAIL DANS L'INDUSTRIE AUTOMOBILE AU BRÉSIL}

\author{
Geraldo Augusto Pinto
}

L'objectif de cet article est d'analyser l'état d'avancement des concepts et des pratiques de gestion du travail appelées "flexibles" dans l'industrie automobile au Brésil, et en particulier celles provenant du Système Toyota de Production. Grâce à une recherche bibliographique et à une étude de cas empirique dans le cadre d'un groupe transnational de pièces détachées automobiles situé à Campinas (Etat de Sao Paulo/Brésil), nous démontrons comment des changements ont eu lieu dans l'organisation du travail, changements liés à l'exigence de nouveaux profils de qualification professionnelle et d'éducation des travailleurs. En conclusion, l'analyse montre bien comment de tels profils - articulés à des méthodes de gestion pour l'évaluation en cours de contrats et de promotions - ont fragmenté le collectif des travailleurs au sein des entreprises, monnayant les relations qui s'établissent au quotidien dans l'ambiance de travail étant donné l'introjection et la manipulation des principes de conduite entre eux afin de servir à laccumulation capitaliste.

Mots-CLÉs: Système Toyota de Production. Sociologie du Travail. Industrie Automobile Brésil.

Geraldo Augusto Pinto - Doutor em Sociologia. Professor do Centro de Educação e Letras da Universidade Estadual do Oeste do Paraná, campus de Foz do Iguaçu, lecionando na Graduação em Pedagogia e no Programa de Pós-Graduação Interdisciplinar em Sociedade, Cultura e Fronteiras. Líder do Grupo de Pesquisa "Estado, Sociedade, Trabalho e Educação" (CEL/Unioeste), pesquisador do Grupo de Pesquisa “Estudos sobre o Mundo do Trabalho e suas Metamorfoses" (IFCH/Unicamp) e membro da Rede de Estudos do Trabalho (RET). Autor dos livros "A organização do trabalho no século 20: taylorismo, fordismo e toyotismo" (2. ed., Expressão Popular, 2010) e de "A máquina automotiva em suas partes: um estudo das estratégias do capital na indústria de autopeças" (Boitempo, 2011). 